\title{
Strategic Integration between U.S. Airways and Iberia in One World
}

José G. Vargas-Hernández

University Center of Economic and Administrative Sciences, University of Guadalajara, Zapopan, Jalisco, Mexico

*Corresponding author: José G. Vargas-Hernández, University Center of Economic and Administrative Sciences, University of Guadalajara, Zapopan , Jalisco, Mexico, Tel: +523337703340, Ext: 25685; E-mail: josevargas@cucea.udg.mx

Rec Date: Sep 30 2014; Acc Date: Oct 08 2014; Pub Date: Oct 152014

Copyright: (C) 2014 Vargas-Hernández JG. This is an open-access article distributed under the terms of the Creative Commons Attribution License, which permits unrestricted use, distribution, and reproduction in any medium, provided the original author and source are credited.

\begin{abstract}
The air transportation is one of the most important international industries; there are three major networks or strategic alliances (One World, Sky Team and Star Alliance). They seek to overcome each other, whilst the members leave the guild and join another. This paper attempts to determine the reasons for the performance of the joint venture and the performance of firms within the alliance.
\end{abstract}

Keywords: Airlines; Antitrust; Firm performance; Strategic alliances

\section{Introduction}

Strategic alliances between firms are ubiquitous phenomena. Strategic alliances are defined as voluntary arrangements between firms involving exchange, sharing or co-development of products, technology or services [1]. Strategic alliances may occur as the result of a wide range of motives and goals that can take many forms and occur along boundaries either horizontal or vertical.

Strategic alliances have three important characteristics:

1. They are intentionally strategic and not tactical.

2. Focus on objectives to long term and greater economic benefits, and

3. Provide very close bonds between the allies, future interest of allies, support the highest levels of each organization and make special emphasis on cooperation and collaboration [2].

In the last two decades, the strategic alliances have increased exponentially according to its quantity. The groups forming of multiple alliances with multiple companies have rooted companies in networks of interaction. This trend leads to the formation of social capital firms in strategic alliances. Social capital is defined by Koka and Prescott [3] as the addition of resources and capabilities that a company gets to enter into a strategic network of lasting relationships between companies, firms or constellation. It is the degree of confidence that the firm may acquire in society.

\section{Background of the Problem}

From the strategic point of view, some of the key factors in the conduct of the company in terms of strategic alliances can be defined if the sequence of moments that occur in the alliance is reviewed. It includes first the decision to form an alliance, the choice of a suitable partner, the choice of alliance structure and dynamic evolution of the partnership while the partnership evolves with the passage of time. Another important issue for strategic alliances is their consequences on performance, both in the performance relationship in strategic alliance as well as the performance of firms entering the alliance [4].

\section{Defining the Problem}

The question of this work lies in what effect on firm performance could be expected from the strategic partnership between U.S. Airways, Iberia, American Airlines and British Airways?

\section{Theoretical Background}

A company under its own initiative identifies the need to enter into an alliance, then, identifies the best partner available and finally chooses a contract that is appropriate to achieve formalize the alliance. Instead, Gulati [5] found that the vast majority of new partnership opportunities were presented to firms through joint strategic allies already obtained. Thus, organizations focused on their existing relationships first searched for possible new partners or searched references to potential allies for allied partners.

The formation of joint ventures to Kogut [6] consists of three main reasons which can also be used for all types of strategic alliances:

1. Transaction costs of reduced number of negotiations.

2. Strategic behavior that leads firms to improve its competitive position or market power, and

3. The pursuit of organizational culture or to learn the results when one or both partners need to acquire a significant knowledge of the other partner.

While partnerships can be seen as a different way of governance than those of markets and hierarchies, there is a considerable difference in the formal structure of the partnerships themselves. The wide variety of organizational structures implies that firms face a set of options to achieve structure their alliances [7]. The different paths of evolution that follow the partnerships can have important consequences on their performance. Therefore, understanding the evolution of alliances provides critical insights on how these links can be managed in the best way. Firms can make significant changes that may change the original design of any part of the alliance once it is already done [8].

To assess the performance of alliances, there have been a number of studies, but they have failed to identify the factors, which include:

1. Flexibility in the management of the partnership.

2. Building trust between the allies, 
3. Constant exchange of information between partners,

4. Constructive conflict management,

5. Continuity of related and responsible for the communication system of the firm and alliance staff, and

6. Manage the expectations of partners, among others.

Among the considerations based on the institutions for strategic alliances, there is a regulatory pillar within which there are two dimensions:

1. First, formal modes of market entry requirements affect alliances and networks, governments discourage or prohibit acquisitions firms.

2. And second, there are antitrust concerns or conspiracy, in which firms establish alliances with competitors in the same industry, and this raises suspicions to the state and society of collusion and monopolies [1].

\section{Brief Review of the Literature}

Most of the literature related to strategic alliances is about partnerships between businesses that share the same profit motive. And researchers almost always agree that only about forty percent of these partnerships are successful. Previous research on strategic alliances has led to valuable insights on the behavior of firms in alliances and their impact on the performance because such relationships.

There have been three main conclusions based on these previous investigations:

1. First, the unit of study adopted is the company or partnership. For example, the researchers have tried to identify the attributes that affect the reason for entering to relationships of alliances and or the choice of partners.

2. Second, it is to examine the formation and performance of alliances in a non-social context. For example, from a standpoint of transaction costs, it is argued that while the lower the competition, the company will be more exposed to negotiations or bargaining of small numbers and other ways of opportunistic actions [9].

3. And third, research partnerships have focused primarily on factors at the level of the company and industry. Andrews [10] in his book proclaimed that the strategic actions of firms are the result of a meeting between the competence of an organization and the availability of new opportunities.

\section{Methods}

To analyze the case of the U.S. strategic integration between Airways and Iberia to One World strategic network, mainly represented by American Airlines and British Airways, it was used a description method, which collects information from the integrations of these firms and the effects of integration into the strategic alliance analyzes was used.

\section{Analysis of Results}

American Airlines has codeshare flights with British Airways to / from and within the UK and Africa, Europe and the Middle East. British Airways is a member of the One World alliance, a network of alliances formed by twelve of the world's leading airlines: American
Airlines, British Airways, Cathay Pacific Airways, Finnair, Iberia, Japan Airlines, LAN, Malév Hungarian Airlines, Mexicana, Qantas Airways, Royal Jordanian and S7. The One World network offers flights to over 750 destinations in nearly 150 countries.

U.S. Airways, as part of the new American Airlines, joins the business with 28 transatlantic routes, of which 27 are new, including direct routes from North America to 18 European destinations. The more than 240 destinations in North America that this agreement provides, it allows to travel through nine distribution centers of American Airlines and U.S. Airways: New York (JFK), Miami, Chicago, Dallas / Fort Worth, Los Angeles, Phoenix, Charlotte, Philadelphia and Washington DC, to cross the Atlantic to Europe in any of the five carriers. On the other hand, in the New York-London route, it has an unrivaled service, with up to 17 daily direct flights between the two capitals and a predominant product in the business segment.

\section{The main benefits of this great deal are:}

1. More flights, more routes, better schedules and connections and a greater number of premium seats.

2. Power to combine airlines and booking that suits the needs of the passenger through a simple transaction.

3. Access to VIP lounges at checkout facilities and luggage for members of loyalty programs, expanding opportunities to obtain and use miles.

4. Providing special assistance to passengers connecting with eleven main entrances to New York (JFK), Miami, Chicago, Dallas, Los Angeles, London Heathrow, Madrid, Helsinki, Phoenix, Charlotte and Philadelphia.

5. A modern fleet: AA B777-300 ER, BA and the B787-380 and Finnair and Iberia and U.S. Airways A-330-300.

6. Increased coordination between companies in case of any incident may occur.

The joint venture includes all scheduled flights operated by U.S. Airways American, British, Iberia and Finnair, members of the One World alliance in which U.S. Airways has just joined in 2014 departing from Star Alliance. As reported by the British press, the compromise between the companies involved assumes revenue sharing. Airlines are allowed to coordinate schedules and prices between North America and Europe.

In July 2010, the Commission of the European Union sets out the legally accepted undertakings offered by airlines British Airways, American Airlines and Iberia, the three, members of the One World alliance. These commitments were offered in response to the concerns of the Commission for the planned strategic alliance between the three aforementioned airlines breaking antitrust rules of the European Union and thus harming consumers of transatlantic routes.

In these commitments, the parties offered that the space for landing and takeoff would be available at London Heathrow airport to facilitate the entry or expansion of competitors on routes between London and New York, Boston, Dallas and Miami. After a market test, the Commission concluded that the commitments offered are suitable to remedy the competition concerns, and has closed the investigation [11].

Since September 2009, the Commission sent a statement of objections, which stressed cooperation between the parties, including benefit sharing and joint management of schedules, pricing and 
capabilities of all routes between North America and Europe. This could break the competition rules of the European Union.

\section{Conclusions / Discussion}

To answer the question on the performance of partnerships: What factors influence the performance of strategic alliances? It is used the characteristics of the partners and the dynamics of evolution that affects the success of partnerships, as well as the influence of the correlation of the partners in strategic networks on the success of their joint ventures [12]. With respect to performance advantages for companies that engage in strategic alliances: Firms derive economic and social benefits of their alliance? Case studies of stock market reactions to announcements of alliances are used. Also, it is important the influence of membership in strategic networks and the relative position in the network performance and business survival [13].

Finally, in response to what effect on firm performance could be expected from the strategic alliance of the study? Regarding the additional values, rarity and consumer benefits that offer the alliance formation. As expected, the performance of the alliance must be successful, as must be the performance of each of the companies that form the strategic alliance. The result of the performance of the alliance is expected to be positive for several reasons.

1. The strategic alliance between American Airlines and British Airways has been successful and the addition of new airlines to the One World Network will be successful.

2. Strategic One World network has long been successful.

3. The competitive advantage achieved through the alliance, such as creating new and unique air routes, the high capacity routes and ease if communication between airlines, take them to a successful partnership.

4. The market to which the airlines in alliiance are focusing has an unattended demand as many daily transatlantic flights are required.
5. The alliance has achieved compliance with the antitrust laws in the European Union and the United States.

6. U.S. Airways left behind a rival to join One World alliance, which should increase the likelihood that the alliance works.

\section{References}

1. Peng M (2010) Estrategia Global. México DF: Cengage Learning.

2. Ball MA, Payne SC (2002) Strategic Alliances: Building Strong Ones and Making Them Last.

3. Koka BR, Prescott JE (2002) Strategic alliances as social capital. Strategic Management Journal 23: 795-816.

4. Gulati R (1998) Alliances and networks. Strategic Management Journal 19: 293-317.

5. Gulati R (1993) The dynamics of alliance formation. Harvard University Press, USA.

6. Kogut B (1988) A study of the life cycle of joint ventures. Cooperative Strategies in International Business6: 169-185.

7. Powell WW (1990) Neither market nor hierarchy: Network forms of organization. Research in Organizational Behavior. JAI Press 12: 295-336.

8. Harrigan KR (1986) Managing for Joint Ventures Success.

9. Williamson O (1985) The Economic Institutions of Capitalism. Free Press: New York.

10. Andrews K (1971) The Concept of Corporate Strategy.

11. http://europa.eu/rapid/press-release_IP-10-936_en.htm.

12. Levinthal DA and Fichman M (1988) Dynamics of interorganizational attachments: Auditor-client relationships. Administrative Science Quarterly 33: 345-369.

13. Dyer JH (1996) Specialized supplier networks as a source of competitive advantage: Evidence form the auto industry. Strategic Management Journal 17: 271-291. 